\title{
Urine carbamate determination compared with plasma pseudocholinesterase for diagnosis of insecticides poisoning
}

\begin{abstract}
Introduction: Diagnosis of carbamate poisoning is frequently missed especially when patients present after the recovery of pseudocholinesterase inhibition. Confusion is due to the similarity of the clinical picture with that of food poisoning and other infectious syndromes.
\end{abstract}

Patients and methods: Patients $(n=40)$ admitted within 4 hours of carbamate intoxication were included in the study. They were graded according to Poison severity score PSS. Normal volunteers $(\mathrm{n}=10)$ were included and served as negative control group. Normal subjects and all patients were tested for plasma pseudocholinesterase (PsChE) within 4 hours and 18 hours from carbamates exposure. Urine carbamate concentration was determined on the $18^{\text {th }}$ hour and 2 days after exposure. Different PSS groups and normal volunteers were compared for their plasma PsChE and urine carbamate levels using student $t$ test and correlation coefficient Method used for PsChE determination is the kinetic assay method. Urine carbamate concentrations were determined by spectrophotometry using modification of the method of Tamrakar. Carbamate determination method was tested for linearity, precision, recovery and limit of detection of the carbamates

Results: PsChE was significantly lower in PSS II compared to PSS I. No significant difference in PsChE was noticed between both patient's groups and normal volunteers on the $18^{\text {th }}$ hour from carbamate exposure. Urine carbamate concentration was significantly higher in PSS II compared to PSS I on the $18^{\text {th }}$ hour and 2 days after exposure. No correlation was detected between the maximum urine carbamate concentration and plasma pseudocholinesterase. The method specificity increased after modification from 76.9 to $91 \%$. Recovery ranged between 95 and $98 \%$. Limit of detection is $0.1 \mu \mathrm{g} / \mathrm{ml}$ and limit of quantification is $0.2 \mu \mathrm{g} / \mathrm{ml}$. The technique is highly reproducible with inter-day precision RSD less than $8 \%$

Conclusion: A better evaluation and diagnosis of carbamate poisoning patients with delayed presentation can be achieved using urine carbamate determination rather than plasma pseudocholinesterase which is often normalized at the time of presentation

Keywords: pseudocholinesterase, carbamate poisoning, urine carbamate concentration
Volume 2 Issue 3 - 2016

\section{El Masry Mohy K,Abdel Azeem Mohamed, Elshebiny Husam A \\ Department of Forensic Medicine and Clinical Toxicology, Ain} Shams University, Egypt

Correspondence: Mohy K El Masry, Department of Forensic Medicine and Clinical Toxicology, Ain Shams University Hospitals, Abbassiah, Cairo, Egypt, Tel +2022776480 I, Fax +20226836674 Email mohymasry@yahoo.com

Received: August 27, 2016 | Published: December 28, 2016

\section{Introduction}

Carbamate insecticides act similarly to the organophosphates in that they inhibit acetyl cholinesterase enzyme (AChE) at nerve synapses and neuromuscular junctions. This inhibition is reversible with spontaneous hydrolysis occurring usually within several hours thus, the inhibition of blood AChE is frequently not evident at the laboratory. ${ }^{2}$ There are two main pharmacokinetic characteristics that distinguish carbamates from organic phosphorus compounds. First, carbamate insecticides do not easily cross into the central nervous system. ${ }^{3}$ CNS effects of carbamates are thus limited. Second, the carbamate-cholinesterase bond does not "age" as in organic phosphorus compound poisoning. In Egypt, poisoning by carbamates is increasing in frequency. Diagnosis is frequently missed when the case is admitted after considerable delay with an almost normalized pseudo-cholinesterase and a normal true $\mathrm{AChE}$ on presentation. In 2011, the poison control center of Ain Shams University received and treated 259 carbamate poisoning cases. ${ }^{4}$ In other hospitals and health care centers, records underestimate outbreaks of carbamates toxic exposure attributing them to bacterial food poisoning. Most of these outbreaks are due to premature crop harvesting. According to agricultural pesticides committee in Egypt the recommended preharvest interval for carbamate application ranges between 7 and 90 days. Rejection of many of the Egyptian agricultural goods by the European Union is commonly due to non-compliant exportation samples containing above allowed pesticides carbamates residues. ${ }^{5}$ Carbofuran, a pesticide, is a major metabolite of carbosulfan, commonly used nematicide in Egypt. Spectrophotometric determination of different carbamates in food residues and biological samples have been described using various coupling reagents ${ }^{6}$ as diazotized trimethylaniline of $0.2-2 \mu \mathrm{g} / \mathrm{ml}^{7}$ or 2, 6-dibromo-4methylaniline, 2,6-dibromo-4-nitroaniline or 2,4,6-tribromoaniline to form stable diazo dye with a satisfactory limit of detection. Other diazotized $p$-aminoacetophenone (DPAAP) was suggested under alkaline condition. The method was sensitive, posed no interference and azo dye was more stable than other various coupling reagents. Compared with chromatographic methods, the spectrophotometric 
determination of N-methyl carbamates was a simple, sensitive, much less expensive and sensitive to parent compounds as well as metabolites. ${ }^{9}$

\section{Materials and methods}

\section{Subjects}

a. Patients (number=40), of all ages and different sexes with positive history of insecticide poisoning were included in the study. Patients who were diagnosed as organophosphorus poisoning were excluded from the study. Patients presenting with a delay of more than 4 hours from exposure, escaping the early changes of carbamates on plasma pseudocholinesterase, were excluded as well. Were as well excluded, patients with malnutrition, acute infectious or inflammatory pathology, chronic liver diseases or inherited disorders of pseudocholinesterase deficiency.

b. Patients were graded according to Persson and co-authors (2007) to grade 0 to grade 4 according to their clinical picture.

c. Normal volunteers (number $=10$ ) were included in this study and served as negative control group

\section{Samples and laboratory tests}

a. Heparinized blood $(3 \mathrm{ml})$ was collected from all patients and volunteers on admission (less than 4 hours from exposure), and 18 to 24 hours after exposure for the determination of plasma pseudocholinesterase. Blood from normal volunteers was taken and daily subjected for pseudocholinesterase

b. Urine samples were collected in contamination-free urine cups for urine carbamate assays, from patients 18-24 hours after exposure then daily thereafter till discharge as well as from normal volunteers.

\section{Methods and procedures}

Quantitative estimation of serum pseudocholinesterase was determined using the colorimetric kinetic method of Young et al. ${ }^{10}$ Chemicals were provided by Diamonds Chemicals Co. The assay depends on the action of pseudocholinesterase on butyrilthiocholine substrate in phosphate buffer resulting in thiocholine. In presence of 5, 5'-dithiobis-(2-nitrobenzoic acid), thiocholine produces 5-mercapto2-nitrobenzoic acid and mixed disulfide. Delta absorbance at $450 \mathrm{~nm}$ is calculated every 30 seconds at $37^{\circ} \mathrm{C}$ to determine pseudocholinesterase activity.

Quantitative estimation of urine carbamates was determined using a modification of Tamrakar et al. ${ }^{9}$ in the following groups of samples

a. Urine samples of 40 intoxicated patients 18 to 24 hours following suicidal or accidental carbamate ingestion were collected for quantitative carbamate determination. Patients with positive history of exposure and clinical picture of carbamate insecticide toxicity in whom pseudo-cholinesterase was tested were included. Urine carbamate level was correlated with plasma pseudo-cholinesterase (within 4 hours from exposure) and clinical picture-based poisoning severity score. ${ }^{11}$

b. Urine of 10 normal volunteers not exposed to carbamate insecticides is processed as the tested samples using double extraction with chloroform. c. Standard drugs and chemicals-free urine samples spiked with various carbosulfan concentrations $(1,2,5,10,15,20$ and $25 \mu \mathrm{g} /$ $\mathrm{ml}$ ) extracted with chloroform and processed as negative and other group samples.

d. Urine samples were processed and extracted the same day of sampling.

e. All samples were tested in duplicates. Standards are tested in triplicates.

\section{Reagents}

a. Carbosulfan Stock solution: $-1 \mathrm{mg} / \mathrm{ml}$ is prepared in $10 \%$ glacial acetic acid

b. Glacial Acetic acid

c. Chloroform Analar (Sigma)

d. $\mathrm{NaOH} 2 \mathrm{~mol} / \mathrm{L}$ solution

e. $1 \%(w / v)$ p- aminoacetophenone (PAAP) in diluted HCL 1:5 $(2.4 \mathrm{~N} \mathrm{HCl})$

f. $0.2 \%(\mathrm{w} / \mathrm{v})$ sodium nitrite aqueous solution was be freshly prepared daily

g. $3 \%(\mathrm{w} / \mathrm{v})$ sulphamic acid aqueous solution

h. Diazotized PAAP (DPAAP): It is prepared by adding fresh $0.2 \mathrm{ml}$ of $0.2 \%$ sodium nitrite solution to $10 \mathrm{ml}$ PAAP and keeping the mixture in ice bath for 20 minutes. Excess nitrite will be removed by addition of $100 \mu 1$ of $3 \%$ sulphamic acid. Better diazotization was achieved when the mixture is placed in ice bath rather than $5 \mathrm{C}$.

\section{Extraction procedure of carbamates from urine, fruits and vegetable samples}

A double extraction is performed with $10 \mathrm{ml}$ chloroform with equal volume of urine. The mixture is vigorously shaken for 5 minutes and vortex. The sample is then centrifuged and the organic layers of the extraction separated and evaporated to dryness under a stream of air. The residue is reconstituted in $100 \mu 110 \%$ glacial acetic acid then diluted by $900 \mu 1$ distilled water to reach $1 \%$ acetic acid concentration. The extract is then diluted with $9 \mathrm{ml} 1 \%$ acetic acid to reach $10 \mathrm{ml}$.

\section{Procedure of carbamate quantitative determination}

The method is based on the coupling of a carbamate pesticide with diazotized $p$-aminoacetophenone (DPAAP) under alkaline condition. The orange dye formed is measured at $460 \mathrm{~nm}$. The procedure is based on a modification of the test described by Tamrakar et al. ${ }^{9}$ To $1 \mathrm{ml}$ blank, urine sample or carbamate standards containing various concentrations $(2-25 \mu \mathrm{g} / \mathrm{ml})$ of carbosulfan in $1 \%$ glacial acetic acid, $2 \mathrm{ml}$ of freshly prepared DPAAP are added and left for 5 minutes. To the above mixture, $0.5 \mathrm{ml}$ of $2 \mathrm{Mol} / \mathrm{L} \mathrm{NaOH}$ is added. Vortex and rapid shaking for 20 seconds aimed to avoid the formation of a precipitate. The color is read at $450 \mathrm{~nm}$ against blank after 5 minutes. The color is stable for one hour. Absorbance is plotted against concentrations on a daily performed standard curve.

\section{Calculation}

A standard calibration curve is constructed. Intra-day and interday precision calculated from the standard samples. Recovery of 
the extracted carbamate from spiked standard samples is calculated. To determine the limit of detection of the equipment for the method assay of carbamates, a negative control sample was run under the experimental conditions to obtain the absorbance baseline noise. A detectable compound should produce a signal that is at least three times the baseline noise [that is, signal-to-noise $(\mathrm{S} / \mathrm{N})$ ratio $=3]^{12}$

\section{Results}

Patients were graded on admission according to Poison severity score PSS ${ }^{11}$ to grade I (19 cases) or grade II (21 cases). All cases of grade I PSS, presented with mild cholinergic signs, sweating, vomiting, diarrhea, irritability and mild dyspnea. In addition, patients with grade II PSS manifested prolonged vomiting and diarrhea, pronounced cholinergic signs, moderate to severe dyspnea, bronchospasm, hypoxemia (4 cases) requiring oxygen supplementation, muscle fasciculations, disturbed conscious level (in 9 cases) and isolated seizure (in 2 cases). Manifestations and signs of toxicity were regressing and disappeared totally after an average of 1.6 days in grade I and 2.2 days in grade II PSS patients. Plasma pseudocholinesterase was significantly lower in grade II than in grade I PSS patients $(\mathrm{p}<0.05)$ on admission, however no significant difference was observed between the two groups 18-24 hours after admission (Table 1). No significant difference between the negative control group and the carbamate intoxicated patients 18-24 hours after admission despite the significant residual manifested symptomatology (Table 2). In both Grade I and II PSS patients, the plasma pseudocholinesterase significantly rose after 18-24 hours from ingestion $(\mathrm{p}<0.00001)$ (Table 1) Urine carbamate levels were significantly higher in Grade II $(9.86 \mu \mathrm{g} / \mathrm{ml})$ compared to Grade I $(3.77 \mu \mathrm{g} / \mathrm{ml})$ PSS patients $(\mathrm{p}<0.01)$. Levels at 18-24 hours in urine confirmed carbamate exposure and confirmed the degree of clinical severity (Table 3). At 48 hours after exposure the urine carbamate levels were still significantly different among the two groups $(\mathrm{p}<0.05)$. In grade I PSS patients, the urine carbamate levels significantly decreased 48 hours $(1.4 \mu \mathrm{g} / \mathrm{ml})$ compared to 18 24 hours after ingestion $(3.77 \mu \mathrm{g} / \mathrm{ml})(\mathrm{p}<0.05)$. Similarly in Grade II PSS patients, the urine carbamate levels significantly decreased 48 hours $(4.64 \mu \mathrm{g} / \mathrm{ml})$ compared to $18-24$ hours after ingestion $(9.86 \mu \mathrm{g} /$ ml) ( $\mathrm{p}<0.01)$. Methyl carbamates urinary excretion decreased by $50.9 \%$ (grade I PSS patients) and $63.2 \%$ (grade II PSS patients) at 48 hours compared to 18-24 hours; however the percentage reduction was not different in both groups (Table 4). No correlation was evident between clinical findings of carbamate-intoxicated patients and plasma pseudocholinesterase 18-24 hours after exposure. No significant correlation $\left(\mathrm{r}^{2}=0.188\right)$ existed between the lowest plasma pseudocholinesterase (less than 4 hours) and urinary carbamates concentration tested 18-24 hours from exposure (Table 5). Table 1 Statistical comparison of plasma pseudocholinesterase PsCHE in different poison severity score (PSS), on admission and 12-24 hours after ingestion using t-test.

Table I Statistical comparison of plasma pseudocholinesterase Ps CHE in different poison severity score (PSS), on admission and I2-24 hours after ingestion using t-test

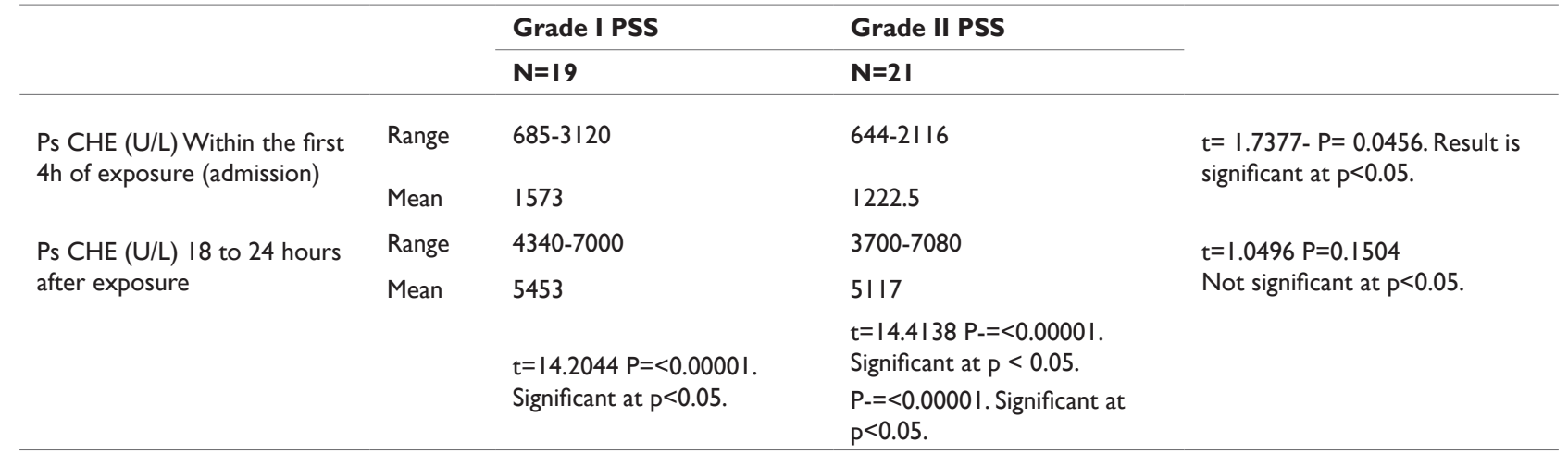

\section{Evaluation of the modified technique}

The linearity of the standard calibration curve with concentrations from 1 to $25 \mu \mathrm{g} / \mathrm{ml}$ is good $\left(\mathrm{r}^{2}=0.989\right)$. Quantification limit is $0.2 \mu \mathrm{g} /$ $\mathrm{ml}$. The limit of detection $(0.1 \mu \mathrm{g} / \mathrm{ml})$ is calculated by an absorbance equivalent to three times that of the negative sample. The technique is highly reproducible with inter-day precision RSD less than $8 \%$. Specificity of the test of $76.9 \%$ is increased to $91 \%$ with some modifications of Tamrakar et al. ${ }^{9}$ Sensitivity of the test decreases when the solutions are not freshly prepared. Diazotization step is improved when PAAP is kept with freshly prepared $0.2 \%$ sodium nitrite in ice bath for at least 20 minutes. Improper extraction occurs with dilute acetic acid. After extraction with chloroform and evaporation the residue is better taken in $10 \%$ acetic acid after which it is diluted to $1 \%$ by distilled water. Precipitation that might develop after addition of $\mathrm{NaOH}$ is avoided by limiting the volume of 2 molar $\mathrm{NaOH}$ to $0.5 \mathrm{ml}$ and vigorous shaking after addition. Recovery of carbamate using this extraction method ranged between 95 and $98 \%$ using 5 and $10 \mu \mathrm{g} / \mathrm{ml}$ standards.

Table 2 Statistical comparison of negative control and patient's plasma pseudocholinesterase (IU/L) 18-24 hours after ingestion using t-test

\begin{tabular}{|c|c|c|c|}
\hline & $\begin{array}{l}\text { Negative } \\
\text { control } \\
n=10\end{array}$ & $\begin{array}{l}\text { Patient's P } \\
\text { ChE* n=40 }\end{array}$ & t-test \\
\hline \multirow[t]{2}{*}{ Range } & $4900-7400$ & $3700-7080$ & \\
\hline & & & $\begin{array}{l}\mathrm{t}=1.5604 \mathrm{P}=0.103 \\
\text { Non-significant }\end{array}$ \\
\hline Mean $\pm S D$ & $5855.5 \pm 849$ & $5315.4 \pm 1003$ & \\
\hline
\end{tabular}

*plasma pseudocholinesterase 18 - 24 hours post-intoxication 
Table 3 Statistical comparison of urine carbamate in different poison severity score, 18 to 24 hours and 48 hours following exposure using t-test

\begin{tabular}{|c|c|c|c|c|}
\hline & & $\begin{array}{l}\text { Grade I poisoning severity } \\
\text { score }\end{array}$ & $\begin{array}{l}\text { Grade II poisoning severity } \\
\text { score }\end{array}$ & \\
\hline \multirow{3}{*}{$\begin{array}{l}\text { Urine carbamate }(\mu g / \\
\mathrm{ml}) \text { I 8-24 hours }\end{array}$} & Number & $N=19$ & $N=21$ & \multirow{3}{*}{$\begin{array}{l}t=4.6-P=0.000022 \text { Significant at } \\
P<0.01\end{array}$} \\
\hline & Range & $0.21-10$ & $4.2-22.25$ & \\
\hline & Mean & 3.77 & 9.86 & \\
\hline \multirow{4}{*}{$\begin{array}{l}\text { Urine carbamate }(\mu \mathrm{g} / \mathrm{ml}) \\
48 \text { hours }\end{array}$} & Number & $N=5$ & $N=15$ & \multirow{4}{*}{$\begin{array}{l}t=2.06-P=0.0268 \text { Significant at } \\
P<0.05\end{array}$} \\
\hline & Range & $0.2-3.3$ & $1.1-11.8$ & \\
\hline & Mean & 1.4 & 4.64 & \\
\hline & & $\begin{array}{l}t=1.856-P=0.0383 \text { Significant } \\
\text { at } P<0.05\end{array}$ & $\begin{array}{l}t=3.495-P=0.00069 \text { Significant } \\
\text { at } P<0.01\end{array}$ & \\
\hline
\end{tabular}

Table 4 Statistical comparison of percentage urinary carbamate concentrations reduction, 18-24 hours and 48 hours following exposure in different poison severity score using t-test

\begin{tabular}{lll}
\hline & Grade I PSS (n=5) & $\begin{array}{l}\text { Grade II PSS } \\
(\mathbf{n}=\mathbf{I 5})\end{array}$ \\
\hline $\begin{array}{l}\text { I8-24 hours Mean conc } \\
(\mu \mathrm{g} / \mathrm{ml})\end{array}$ & 3.77 & 9.86 \\
$\begin{array}{l}48 \text { hours Mean conc } \\
(\mu \mathrm{g} / \mathrm{ml})\end{array}$ & $\mathrm{I} .4$ & 4.64 \\
$\begin{array}{l}\text { Range of concentration } \\
\text { reduction }(\%)\end{array}$ & $34-76.4 \%$ & $34.5-77.6 \%$ \\
$\begin{array}{l}\text { Mean of concentration } \\
\text { reduction }(\%)\end{array}$ & $50.90 \%$ & $63.20 \%$ \\
\hline
\end{tabular}

Table 5 Correlation between the maximum urine carbamate concentration and plasma pseudocholinesterase

\begin{tabular}{|c|c|c|c|}
\hline & Mean & Range & $\begin{array}{l}\text { Correlation } \\
\text { coefficient }\end{array}$ \\
\hline Plasma & & & \\
\hline $\begin{array}{l}\text { Pseudocholinesterase } \\
\text { in IU/L } \\
\text { (within the first } 4 \text { hours) }\end{array}$ & $130 \mid .8$ & $644-7080$ & $\begin{array}{l}r^{2}=-0.188 . \text { No } \\
\text { significant }\end{array}$ \\
\hline $\begin{array}{l}\text { Carbamate urinary } \\
\text { excretion in } \\
\mu g / \mathrm{ml} \text { on the } \\
18^{\text {th }} \text { hour }\end{array}$ & 6.97 & $0.21-22.25$ & correlation \\
\hline
\end{tabular}

\section{Discussion}

Patients affected with vomiting and diarrhea suggesting mild carbamate poisoning or food borne illness frequently presents late escaping the significant decrease of plasma pseudocholinesterase which is maximally inhibited 45 minutes after oral ingestion. ${ }^{13}$ Clinical differentiation is sometimes difficult. In this study it is evident that plasma pseudocholinesterase is normal 18 hours after ingestion of carbamates regardless of the severity of carbamate poisoning. Confirmation of poisoning was achieved by urine carbamate levels 18 hours after ingestion when laboratory confirmation was no more possible by plasma pseudocholinesterase. Although plasma pseudocholinesterase in PSS II patients is significantly lower than in milder clinical cases (PSS I), yet no significant difference was evident in plasma pseudocholinesterase between negative control and different severity score patients after 18 hours from exposure. According to EPA, ${ }^{14}$ unless a substantial amount of N-methyl carbamate has been absorbed and a blood sample is taken within an hour or two, it is unlikely that blood cholinesterase activities will be found depressed since enzyme reactivation occurs in vitro as well as in vivo. It is a commonly recommended, in clinical practice, to start atropine treatment and not to wait for test result. Presence of atropine refractoriness is a clinical confirmation of severe carbamates or organophosphorus toxicity. Problems in laboratory confirmation of diagnosis and assessment of severity score after the first few hours of poisoning evidently appear easier with identification and quantification of N-methyl carbamates metabolites in urine. Evidently urinary carbamates levels were significantly higher in PSS II than in milder PSS I patients. This significant difference still existed after the elapse of 48 hours from carbamates exposure elaborating the significance of the urinary carbamates test in such patients. Clinical diagnosis of carbamates poisoning is not always rapid and condition is not always benign. Differentiating carbamates from organophosphates based on clinical presentation is often difficult because of the similarity of symptoms, yet urgent treatment decisions must often precede analytical or historical confirmation. Atropine is the primary drug used to treat symptomatic cases involving both organophosphate and carbamate insecticides. ${ }^{15}$ Methomyl, a highly toxic N-methyl carbamate, has been reported to cause a fulminant hepatic failure and death. Fatal outcome often results following respiratory depression and pulmonary edema ${ }^{16}$ Urinary elimination of carbamates has been scarcely studied in man. In rats, carbamate insecticides are well absorbed across skin and mucous membranes, and by inhalation and ingestion. Peak serum levels of some compounds are measured 3040 minutes following ingestion. ${ }^{1}$ It was found that $32-37 \%$ of a dose is excreted in 20 hours $^{17}$ while $75-80 \%$ of 1-naphthyl-N- methyl carbamates (carbaryl) are eliminated in the expired air and urine in 48 hours of larvae. ${ }^{17}$ Carbofuran is eliminated by conjugation in the urine $(14-15 \%)$ or in expired air (45\%) of rats. ${ }^{18}$ Most carbamates undergo hydrolysis, hydroxylation, and conjugation in the liver and intestinal wall, with $90 \%$ excreted in the urine within 3 days. ${ }^{19}$ In intoxicated patients the symptoms start at 20-30 minutes following ingestion. This onset corresponds to the peak described by Flomenbaum et al. ${ }^{1}$ Symptoms also correlated with peak Carbofuran concentration at 30 minute following oral ingestion. ${ }^{13}$ Carbamates and metabolites urinary concentrations were maximal at 18-24 hours. It was diminished 36 to $79 \%$ at 48 hours. Although urine carbamate levels were significantly higher in grade II compared to grade I PSS patients, yet levels did not correlate with plasma cholinesterase maximum inhibition within 
4 hours from ingestion. This might be explained by the variability of carbamate elimination. Toxicokinetic of carbamates in humans is apparently similar to that of rats; however more controlled studies are warranted for the description of carbamates toxicokinetic in humans. ${ }^{20}$

\section{Conclusion}

A better diagnosis and severity assessment of carbamate poisoning patients with a delayed presentation can be achieved using urine carbamate determination rather than plasma pseudocholinesterase which is often normalized at the time of presentation.

\section{Acknowledgements}

None.

\section{Conflict of interest}

The author declares no conflict of interest.

\section{References}

1. Flomenbaum NE, Goldfrank LR, Hoffman RS, et al. Insecticides: Organophosphorus and carbamates. Goldfrank's Toxicologic Emergencies. 8th ed. USA: McGraw-Hill; 2006. p. 1497-1512.

2. Ramesh C Gupta. Carbamate Insecticides Toxicity. The Merck Veterinary Manual. 2012.

3. Gallo MA, Lawryk NJ. Organic phosphorus pesticides. In: Hayes WJ, Laws ER, editors. Handbook of Pesticide Toxicology. USA: CA Technologies, Academic Press; 1991. p. 917-1090.

4. El Masry MK, Tawfik H. 2011 Annual Report of the Poison Control Centre of Ain Shams University Hospital, Cairo, Egypt. Ain Shams Journal of Forensic Medicine and Clinical Toxicology. 2013;20:10-17.

5. Egyptian commerce service. Commercial guide to Egyptian Exporter to European Union. Egyptian Embassy, Bruxel, Belgium, Europe; 2012.

6. Manjubhashini AB, Raman GK, Kumar AS, et al. A simple spectrophotometric technique for the determination of carbaryl pesticides in various environments. Talanta. 2003;59(5):1015-1019.

7. Alvarez-Rodríguez L, Monferrer Pons L, Esteve Romero JS, et al. Spectrophotometric determination of carbamate pesticides with diazotized trimethylaniline in a micellar medium of sodium dodecy sulfate. The Analyst. 1997;122(5):459-463.
8. Kumar KS, Suvardhan K, Rekha D, et al. Facile and sensitive spectrophotometric determination of carbosulfan in formulations and environmental samples. Environ Monit Assess. 2007;129(1-3):271-276.

9. Tamrakar U, Pillai AK, Gupta VK. A Simple Colorimetric Method for the Determination of Carbofuran and its application in Environmental and Biological Samples. J Braz Chem Soc. 2007;18(2):337-341.

10. Young DS, Pestaner LC, Gibberman V. Effects of Drugs on clinical laboratory tests. Clin Chem. 1975;21(5):1D-432D.

11. Persson HE, Sjoberg GK, Haines JA, et al. Poisoning severity score. Grading of acute poisoning. J Toxicol Clin Toxicol. 1998;36(3):205-213.

12. MaštovskáK, Lehotay S. Practical approaches to fast gas chromatographymass spectrometry. J Chromatogr A. 2003;1000(1-2):153-180.

13. Renzi BE, Krieger RI. Sublethal Acute Toxicity of Carbosulfan [2,3dihydro-2,2-dimethyl-7-benzofuranyl(di-n-butylaminosulfenyl) (methyl)carbamate] in the Rat after Intravenous and Oral Exposures. Fundam Appl Toxicol. 1986;6(1):7-15.

14. EPA. N-Methyl Carbamates. Environmental Protection Agency. Handbook Chapter5. 2013.

15. Martinez Chuecos J, Molinero Somolinos F, Sole Violan J, et al. Management of methomyl poisoning. Hum Exp Toxicol. 1990;9(4):251254.

16. Agha A, Dib S, Al Hakami M, et al. A Fatal Case Of Methomyl Poisoning Leading To Fulminant Hepatic Failure. The Internet Journal of Toxicology. 2008;7(1):1-5.

17. Hassan A, Zayed SMAD, Abdel Hamid FM. Metabolism of carbamate drugs. I. Metabolism of 1-naphthyl-N-methyl carbamate (Sevin) in the rat. Biochem Pharmacol. 1966;15(12):2045-2055.

18. Ferguson PW, Dey MS, Jewell SA, et al. Carbofuran Metabolism and Toxicity in the Rat Toxicol. Fundam Appl Toxicol. 1984;4 (1):14-21.

19. Nye DE, Dorough HW. Fate of insecticides administered endotracheally to rats. Bull Environ Contam Toxicol. 1976;15(3):291-296.

20. Zayed SMAD, Hassan A, Hussein TM. Metabolism of carbamate drugs-II: Degradation of 1-naphthyl-N-methyl carbamate (Sevin) in adult larva of the cotton leaf worm (Prodenia litura F.). Biochemical Pharmacology. 1966;15(12):2057-2064. 